\title{
Borrowings or Foriesterisms
}

\author{
Brikena Furxhi
}

Lecturer, Aleksander Moisiu University, Durres, PhD Candidate, University of Tirana

Doi:10.5901/jesr.2014.v4n4p65

Email: brikenafurxhi@hotmail.com

\section{Terminological Debate}

Albanian language along with standard and dialectal variants that vivify inside, is the mean of communication for speaking community in a wide geographical area with historical contexts and socio-cultural development of its being thus transformed into a social phenomenon, if we use a definition of Sosyr , but not only. It remains one of the main indicators of ethnicity as a marker of the history and culture of this nation also turning in his identification.

Through this community language speakers enables the creation of bridges o communication with the neighboring peoples or not, which arises between an exchange of cultures, ideas, information, achievements etc.. This linguistic relationship is created between languages in contact, creates a passage of words from one language to another is called a loan. This term has already been part of the linguistic terminology, although not return after the note speech borrow.

But, let's first look at the meaning of this word by Albanian of Today's Vocabulary: "Rent or "borrow": money or something else of value given or taken someone for a certain time and back again. With the right question: Should reviewed this term, when some of the borrowings of Albanian itself have become part of its lexical corpus ( without being turned away from the language has taken them) and has the Albanian language the possibility with its dough and tools to create a new term to designate this language process?

This terminological debate should analyze whether it is worth today, in our days, the replacement of the term should remain the same until it is transformed into a international linguistic term. Is an inner need of the Albanian people to change this term, while it has all the possibilities to create neologisms? Here, I think, requires a revision of the term by the linguists, researchers, who can throw it in a nationwide discussion to gather ideas and opinions about this terminology.

As a matter of fact the term borrowing was not entirely new : as early as 1921 E.Sapir dedicated a chapter of his book "Language" to inter-linguistic influence and said that the simplest way a language can influence one another is the borrowing of words. He also mentions cultural borrowing which happens each time a new cultural trend is being introduced into a society, that brings along new loan words. The term borrowing, although having been used for so many years, has in a way being misleading from the semantic point of view and several scholars have noticed that can not speak of borrowing in a strict sense, as it would imply the source language temporarely lending one of its forms to the target language and expect to be returned which of course, is impossible. In spite of the mentioned inadequacy the term has persisted.

\section{Borrowing Causes}

This phenomenon has emerged in fact, earlier when in his origins the human and human societies have had to communicate to interact in the same social group or different groups to solve problems that were encountered. Through language they do not realize just communication, but representing cultures, as well as the meeting points of civilizations and exchanges among peoples.

Later,Ascoli in his book "Scritti sulla questione della lingua" Torino 1975 sees these linguistic phenomenons not as a result of isolation, but the presence of people and influence over each one to another between communities of speakers. Here we also find use for the first term: forestierisem. Loan itself is a very complex linguistic phenomenon that arises therefore from contact between two linguistic cultures. Under its influence the languages rich and evolve. Bloomfield said that there are two types of loan: direct and indirect.

Direct loan occurs when two languages are used in the same community topographicly and politically, therefore, the word goes out from one language to the other, while indirect borrowings occur between two nations that are not one politically, the foreign word comes through the language to the lexicon of the language that borrows it. 
For example: borrowings from Italian into Albanian into the current speech of Albanian immigrants living in Italy, are direct. Borrowings from the Italian used in Albanian territory through a third kind of speakers, are indirect.

Borrowings in the lexicon of the borrowings Albanian language are embedded throughout the years, which have become part of the formative, as well as semantic vocabulary of Albanian people. Albanian such as: tray, ball ,pocket, city, street, friend, etc.. Besides constantly towards their language, especially recently encountered increasingly unembedded borrowings which compete unfairly Albanian own words becoming the barbarisms that violate our language. So, we have such as: update, engagement, commitment, experience, influence, implement. Entry into new languages of words is due to the need to respond to the overall economic development, social and cultural development of the country. The arrival of new concepts through new words, most of which are international words / terminologies, are the main tool of increase of this lexical system of language itself and any other means of communication can not convey the modernization of society without reaching the stage of the modernization of the language. This is because, as E.Sapir said himself : "Languages, as civilizations rarely sufficient to themselves." But, nowdays, the terminology and its use is shown as an important problem. The entrance of the foreign words in the overall lexicon is more limited, their acceptance allowed even less than in the terminological lexicon which carries the heavy of borrowing-words from other languages, converting the terminology in the principal gate of entrance of the foreign lexicon. A special type of loan are national words that during the years are also taken from other languages. J.Kole in his paper "Place of national words among Albanian borrowings" ("Our Language" 1/1987) states that when it comes to national words, we consider the extent of their spread in a few or more other languages. When a national word replaced with another word or translated by an Albanian word, then it is no longer national word and passes the rest of the borrowings. Albanian language as international terms has the words: body, bone, cocoa, typhoon, tank , taige, etc.. Their distinctive feature is their stability in the Albanian vocabulary compared to other Albanian borrowings.

From the sociolinguistic perspective remains essential to recognize the reasons of transfer of a word from one language to another in a given situation and historical linguistic, by a group of speakers, prone to use these borrowings $/$ foreign words in their language special registers.

Loan itself mainly affects lexical corpus of a language (therefore we call lexical borrowings), as this is the most sensitive part of the system of a language and the most prone to changes. Following the criterion of their diachronic distribution, we distinguish Albanian borrowings: graecisms, Latin and continued after the Roman period Albanian impacts from the Romance languages came from Latin: italian and french especially, turkisms, slavicisms, recently, by English

So, what are the causes of their birth? Could it be that at certain stages of the life of a language, it may face more challenges, which arise from the pressure of the influx of these foreign words? What should make this language to survive, to save her vocabulary or cohabits with being forced to accept a portion of these foreign words in its vocabulary? Specifically what?

Borrowing remains the leading cause of contact between the two languages. Impacts between the languages are as old as language itself. And in the context of these impacts Albanian has survived . The most affected part by these linguistic and extralingual pressures remains the lexicon so, its vocabulary. For example : in her difficult historic journey , long occupations of Albania over the years by the Greeks, Romans, Turks, Slavs have made possible the use of these borrowings in our language.

But can stress lately, especially after the fall of communism in Albania ,after the 90s, the main causes are:

1. changes that took place in a new way of governance, territorial division, the names of government institutions as well as state administration, the emergence of private property and of a new economic relationships in society.

2. Increase the intensity of movement of Albanians (as immigration) towards Balkans, Europe and all around the world.

3. studies, employment of its citizens abroad.

4. flow of information in a variety of foreign languages in a very short time via the Internet and the latest technology equipment.

5. trading exchanges, cultural relations between peoples, in which the introduction of a new product in our territory, require the introduction of its designation in parallel.

6. flow of a myriad terminologies that come along with new concepts, inventions, ideas taken from different states.

In the new conditions of globalization, an open society like the Albanian society, today, is under a great preassure of the nations that being politically and economically are powerfull, which we are in contact with. Sh.Islamaj as expressed in "Language and identity" Tirana, 2008, p.52: "Is it a language that will withstand the 
demands of Albanians increased communication and pressures every time the largest outside? It can be said that it is going to be found in situations that are found today and other prestige languages standards with similar opportunities ... In this coping road it will need to address all layers of linguistic first of own resources, dialects and idioms organic, will address the foreign sources, as do finally all languages in the intense development processes of their social, cultural, economic, technological fields". So ,today we see two contrasting movements operating in Albanian language:

1. The movement related to cleaning and the "purification" of its foreign words and barbarisms that are suffocating Albanian. This movement has its genesis in the renaissance period, during which writers like K.Kristoforidhi, Naim, J.Vreto, Sami, etc. was admitted as the fundamental task of Albanian vocabulary enrichment of it by staying away borrowings. Later, in the nineteenth century in the albanian lexicon had great movement, many words came from the dictionary of Albanian, many others were born and came into use. After declaring the independence in 1912, was not followed on with the cleaning power of the Albanian language of foreign words, as they had begun Renaissance. Distinguished some isolated efforts of patriots like: L.Gurakuqi, A.Xhuvani, P.N.Luarasi, M.Logoreci, etc, for cleaning turkisms mainly from Albanian, although some of therms were already become part of the Albanian lexicon. The movement follows after the end of World War II with the persistent work of researchers: E.Lafe, J.Thomai, R.Memushaj, I.Ajeti, Gj.Shkurtaj, etc.

2. The movement as the "modernization" of its related latest fashion and trends to liberal foreign words commonly used in mass media: through the media, newspapers, magazines, television, politicians' debates, etc., that to highlight the preparation and snobbery of some Albanian intellectuals. This movement is motivated by the fact that Albanian, emerging from a long period of isolation under communism, has inherited a poor vocabulary, foreign words to see as a breakthrough or innovation, but this argument does not bring them justifies to don't use these tools not only in the jargon of the day, but also in bookish register. This trend can be only two reasons through which can be explained:

1. Some of the intellectuals do not recognize their own language as well, as to use its words in in the place of foreign words.

2. 2. The absences in their culture' language, but above all an awareness of the deficient value of their parent's language. However, this remains a concern not only for Albanian today. We can mention: the impoverishment of vocabulary, syntax banalization, mixtures of dialects, spelling deformities, etc. This reminds us of Konica, which postulated for illiterate diploma: "I now see a dark crowd of illiterates with diploma in their pocket, which is rushing towards Albanian and want to put a knife in its back, then to carve shape they like them; that the poor men remember that language is a piece of wood without soul. Do not know who is not only alive, and very thin, so much, is a little deformed knot or a vein, the whole body sways, suffers and loses strength with beauty. Meanwhile prof.Gj.Shkurtaj would translate with Sociolinguistics terms the transition from socialism to democracy, he would see it as a shift from a very high rating for its language and culture in a complete freedom in a position ready to open heedless of unified language and culture of language in general. Consequences: added flow and the irrepressible unnecessary foreign words, increased foreign terms instead of English terms, where the worst example of rulers give the politicians. ("Weight of the Albanian word" p.g.354). But foreign words spoil if they accepted the language used when riddles language has its own vocabulary. Over the years they can be accepted and used in those cases when they bring a new meaning, a new semantic nuance, a stylistic or emotional coloration that does not give people the tools here albanian. Remember that uses of borrowings (foreign words ) with stylistic feature in "The rise and fall of comrade Zylo" (phrase transparent inner impulses, abnormal disparities within normality of image ..) or by Kadare in "The File on H" (tonight is just the aksham, is neither evening, nor soir, vjeçer(Turkish word) much less, but is aksham), Turkisms that Noli uses in "March of Barabai" as :motherland, millet, derbederët, jabanxhinjtë, fajdexhinjtë, etc..

Today, the right question is what to do Albanian society and albanian linguistics. The answer was and is clear: Protecting language belongs primarily state and state institutions that depend on a social reproduction. I want only to remember the words of A.Xhuvani in "Linguistic Studies" ,Tirane 1956: "As is known, the Albanian language, during many centuries has lost its own words, that are replaced by the words taken from foreign languages: Turkish, Slavic, etc., which some of us are trying to bring out from their own language and for substituted them , as long as possible with the Albanian words, preserved and founded in people's mouths. Not all, but many of these words, that are being lost, rowing and looking everywhere, can be found again in our language as forgotten words, but with a different meaning from that first one ; a work that happens in every language permanently, because this, as a living 
organism that is, evolution makes no interruption by the semasiological and phonetic changes.

\section{Borrowings' Fields Nowdays in Albanian}

In the conditions of an open society facing the changes, Albanian language will be forced to "open the doors" in front of this influx of new words, which for many reasons do not find their riddles in its vocabulary.

This is conditioned by the trends and main areas towards which we aspire as a nation developing and changing. These rhythms and intensity has been accelerated changes linguists and language itself facing dilemmas that, if they will be able to respond with word-tools or neologisms spread of these concepts, inventions, etc..

This is because it is known already that the linguists are reaching in the "gates of informatics" ever more delay. Specifically informatics has become today an integral part of everyday's life of many of us with the English language too, as its instrumental language. All of us have encountered terms: drive, manual, mouse, software, modem, etc, when we were working, but very few of us have thought to translate these english terms.

Efforts have been, but have proved somewhat unsuccessful, for example: monitor-ekran, password-fjalekalim, memory-kujtese, but do you translate mouse-miu or drive-ngas makinen. This movement should elaborate, because not all people have knowledge of the english language, although she is putting its dominant role in the EU and beyond.

The main areas of use of foreign words today are:

1. political - social field with words like: majority, integrity, coordinate, assign, discouraging, conclusion, destination, actually, aggravate, influence, promote, diversity, bilateral, hegemonic, draft, summit, etc..

2. science' s field and technology: computer, software, modem, ezauroj, mental, etc.

3. the sport's terminology:feirplei,

4. Medicine:medicament, koncentruar, distonike Etc.

At last, lexical borrowings, regardless of the source language, must be stratified according to their value in nowdays Albanian language, by emotional coloring, according to the level of use and territorial restriction.

That means that the value of lexical borrowings in Albanian language revealed through facing with Albanian word.

But this is not the only problem with foreign words in our language. We have to resolve the problem of their orthography, notably proper nouns. That is another challenge of our language today.

\section{References}

"Lexicology of albanian language" J.Thomai, Tirane 2006

"Open window of albanian" Kristina Jorgaqi, Tirane 2008

"Albanian in conditions of globalization" Shezai Rrokaj, april 2013

"Language and identity" Sh.Islamaj, Tirane 2008

"Linguistics studies" A.Xhuvani, Tirane 1956

"The weight of albanian word" Gj. Shkurtaj , Tirane 2009

"The place of international words among albanian's borrowings" J.Kole, Tirane 1987

"The Vocabulary of nowdays Albanian Language" Tirane 2002

"Stylistics of Albanian Language and Pragmatics" Xh.Lloshi, Tirane 2005

"For Albanian Standart" R.Memushaj, Tirane 2012

"Philosophy of Language" Sh.Rrokaj, Tirane 2010 